\title{
Macroplastic in Seabirds at Mirny, Antarctica
}

\author{
Sergey Golubev
}

Papanin Institute for Biology of Inland Waters, Russian Academy of Sciences, Borok, Nekouzskii raion, 152742 Yaroslavl oblast, Russia; gol_arctic@mail.ru; Tel.: +7-910-972-4365

Received: 28 October 2020; Accepted: 3 December 2020; Published: 8 December 2020

Simple Summary: Observations of Antarctic birds eating plastic began to appear in the early 1980s. Plastic debris makes up the majority of marine debris around the world, and pollution is a serious threat to marine wildlife. Threats represent two types of biological interactions with plastic: entanglement and ingestion. This paper describes interactions of seabirds with plastic in Russian Mirny Antarctic station and draw the attention of society to the existing problem. In 2012/2013 and 2015/2016, year-round observations of the author were carried out at Mirny and Haswell Islands, East Antarctica. One case of entanglement of Adélie penguin in a fishing line has been identified; one case of an adult emperor penguin mistakenly ingesting plastic braided rope and subsequently feeding it as part of a food lump to the chick; and two cases of plastic found in south polar skuas. Entanglement and ingestion of plastic by seabirds are rare events. They signal us about problem that needs to be included in the observation program for the health of seabirds and mammals of the Haswell islands. Reducing plastic pressure on natural ecosystems is an important challenge for humanity in the near future.

Abstract: Plastic debris makes up the majority of marine debris around the world, and pollution is a serious threat to marine wildlife. Threats represent two types of biological interactions with plastic: entanglement and ingestion. This paper describes interactions of seabirds with plastic in Mirny and draw the attention of researchers to the existing problem. In 2012/2013 and 2015/2016, year-round observations of the author were carried out at Mirny station and Haswell Islands (area of about $12 \mathrm{~km}^{2}$ ), east Antarctica. One case of entanglement of a molting adult Adélie penguin (Pygoscelis adeliae) in a fishing line was been identified; in addition to one case of an adult emperor penguin (Aptenodytes forsteri) mistakenly ingesting plastic braided rope and subsequently feeding it as part of a food lump to the chick, and two cases of macroplastics found in pellets of south polar skuas (Catharacta maccormicki). Registrations of entanglement and ingestion of macroplastic by seabirds in Mirny are rare. They signal to us about problem that needs to be included in the monitoring for the health of terrestrial biota of the Haswell archipelago.

Keywords: entanglement; ingestion; fishing line; macroplastic; Mirny station; pollution; seabirds; Antarctica

\section{Introduction}

Plastics are a diverse group of synthetic polymers that have their origins in the late 19th century [1]. Further, plastic acquired commercial interest for development in the 1930-1940s [2], but its mass production began in the 1940-1950s [3,4]. Plastic debris currently constitutes the majority of marine debris worldwide, making plastic pollution a global environmental problem and a serious threat to marine wildlife $[5,6]$. However, little is known about plastic longevity and its effects on organisms [3].

At the end of the 20th century, floating plastic debris was not yet a problem in Antarctica, and unusually low levels of plastic pollution in comparison with other areas of the oceans were 
documented there [7]. Currently, plastic debris is found in the most remote and deepest parts of the planet, but debris accumulation rates are much lower in the Southern Hemisphere, although they have been increasing significantly over time [3]. The concentration of macro- and microplastics in the Southern Ocean is decidedly lower than the neighboring temperate waters and even more so than in other parts of the world [8]. However, it is known that the amount of debris in the oceans appears to have stabilized over the past decade, but has increased on the coastline [3].

Records of Antarctic bird species consuming plastic could be dated as early as the 1980s $[1,9,10]$. More than 30 years ago, in some areas of Antarctica, plastic had not been observed in south polar skuas (Catharacta maccormicki), emperor penguins (Aptenodytes forsteri) or Adélie penguins (Pygoscelis adeliae) [7]. However, already at that time, plastic had been found in birds on the sub-Antarctic islands and directly off the coast of Antarctica, for example [11,12]. Evidence of ingestion of plastic by seabirds was obtained on Heard Island in the southern Indian Ocean [13], one of the closest sub-Antarctic islands to Mirny.

Threats to marine wildlife are mainly presented by two types of biological interactions with plastic (macroplastics): (1) ingestion, namely debris being intentionally or accidentally eaten and entering the digestive tract of organisms, and (2) entanglement, predominantly in packaging tapes, synthetic ropes or drifting nets, where loops and holes in various types of debris entangle parts of the animal's body or capture the animal completely $[5,12,14]$.

There are forecasts that the consumption of plastic by seabirds will have reached $99 \%$ of all species by 2050 [6]. Entanglement in plastic debris also poses a very serious threat to the continued survival and wellbeing of marine animals [5]. For instance, seabirds with a distinct plastic load were noted to reduce food intake, which limits their ability to build up body fat, subsequently reducing fitness [15].

The effect of plastic on birds of the Haswell archipelago was not raised to the rank of a problem requiring special attention, since no targeted studies of its occurrence in Antarctic birds in this area had been carried out. However, ingestion and entanglement in plastic is still found both onshore and in the ocean. Recent records of plastic debris in Antarctic penguins and south polar skuas in the archipelago area are already raising concerns and this could pose a major threat for terrestrial biota in the foreseeable future.

This article complements the previously initiated series of publications on the health of Antarctic birds in the Haswell archipelago [16,17]. The purpose of the message is to describe the facts of the interaction of seabirds with plastic in Mirny and to draw the attention of researchers to the existing problem.

\section{Study Area and Methods}

Plastics registration in seabirds was established at the Russian Mirny Antarctic research station $\left(66^{\circ} 33^{\prime} 11^{\prime \prime} \mathrm{S}, 93^{\circ} 00^{\prime} 35^{\prime \prime} \mathrm{E}\right)$ and the Haswell Islands (Davis Sea, east Antarctica, Figure 1) in an area of about $12 \mathrm{~km}^{2}$ during the author's observations-made from 8 January 2012 to 7 January 2013, and from 9 January 2015 to 14 January 2016. The station is located on the edge of Antarctica, with the islands of the archipelago being no more than $3 \mathrm{~km}$ away from it. 


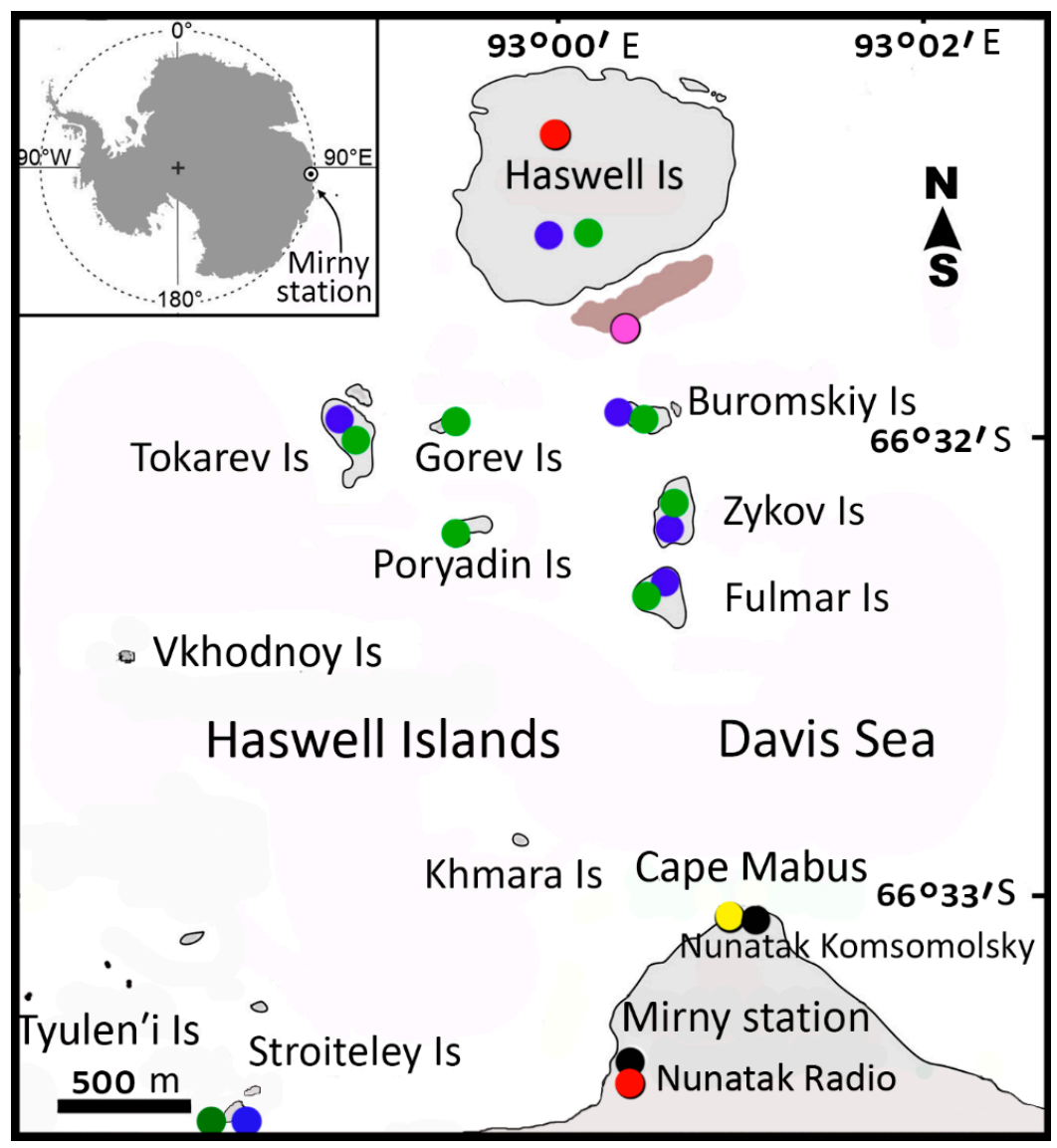

Figure 1. Study area (in the inset in the upper left corner is the location of Mirny station). Note: brown spot-emperor penguin (Aptenodytes forsteri) colony; blue dots-colonies of Adélie penguins (Pygoscelis adeliae); green dots-breeding areas of the south polar skuas (Catharacta maccormicki); red dots-places where plastic was found in pellets of the south polar skua; pink dot-the place where plastic was found in emperor penguins; the yellow dot-the place of the entangled Adélie penguin; black dots — nunataks.

Daily observations were carried out in Mirny at the nunataks of Radio, Komsomolsky and between them; the Haswell Islands were visited on foot during the landfast ice period (April-December). In 2012 there were 46 trips, whereas in 2015 there were 15 trips to the islands and to the emperor penguin colony. The duration of work on the islands and sea ice ranged from $3-5 \mathrm{~h}$, in Mirny-from 1 to $8 \mathrm{~h}$ a day.

In 2012, in order to find out the reasons for the deaths of chicks in the colony of emperor penguins near Haswell Island, 30 frozen chicks of emperor penguins of different ages and at different times were collected. In all chicks, the digestive tracts, the external condition of the skin and the surface of the body under the skin were examined for the presence/absence of hematomas and other physical injuries.

In order to study the qualitative composition of the diet of south polar skuas, 55 pellets were collected and examined in 2012/2013 and 2015/2016. Of these, 12 pellets were found at the Mirny station and in its vicinity (marine or continental ice, nunataks), and 43 pellets coming from Haswell Island near skuas' nests or in their foraging areas.

The examination of dead emperor penguin chicks and determination of the composition of prey remains of south polar skuas were carried out in laboratory conditions with the linear dimensions of the objects being measured to an accuracy of $\pm 1.0 \mathrm{~mm}$ by means of a Vernier caliper.

\section{Results and Discussion}

Four cases of interaction of seabirds with plastic were recorded. In February 2015, a single adult molting Adélie penguin at Cape Mabus (nunatak Komsomolsky) became entangled with its right leg 
being caught in a ball of fishing line, later identified as a local source from Mirny, which was partially frozen into the ice. The penguin was freed, but its leg was injured. After successfully completing the molt, the penguin left Cape Mabus, exhibiting some awkwardness in the snow and ice.

The case of an Adélie penguin being entangled in a fishing tackle at Mirny is not unique to east Antarctica. For example, at the end of the last century, cases of entanglement of Adélie penguins and south polar skuas in fishing nets, including fatalities, were recorded near the Australian Antarctic stations Davis and Casey [12].

A total of 265 bird species have been recorded worldwide, entangled in plastic or other synthetic materials. Of these, 147 species were seabirds. In the order Sphenisciformes, out of 18 living species of penguins, seven (39\%) species were identified entangled in plastic. Fishing lines and nets were responsible for most cases of entanglement in seabird records, with $83 \%$ of species entangled in fishing gear [18]. Among the entangled seabirds of the world fauna, representatives of the order Sphenisciformes are the least common [14].

Among 30 frozen emperor penguin chicks, one had apparently died 1.5-2 h earlier (chick found on 8 October 2012), its age being estimated by the author at 55-60 days. The chick's injuries included its left eye being covered with an inflammatory condition, and an extensive hematoma found on the body under the skin, coupled with the stomach containing gastroliths, squid beaks, and a fragment of green synthetic rope braided from fishing lines $230 \mathrm{~mm}$ long and $5 \mathrm{~mm}$ wide. The piece of rope in the chick's stomach had the shape of a dense lump $35 \times 17 \mathrm{~mm}$ in size [19]. The plastic lump occupied the entire volume of the stomach.

Plastic could have entered the chick's digestive system only with a food lump when fed by one of the adult individuals of the pair. Most likely, one of the adult birds had swallowed a plastic braided rope somewhere in the sea mistaking it for prey. Fast ice at that time of the year could have reached or been close to its maximum width, that is, extending northward up to $30-40 \mathrm{~km}$ from the coastline of Antarctica. A piece of plastic braided rope could have been brought from the east by the oceanic circumpolar current; the less likely cause is the result of expeditionary activities.

At two months of age, the chick was not able to free the gastrointestinal tract from plastic on its own. Direct evidence of the death of the chick from the ingestion of macroplastic into the digestive system was not obtained. The blockage of the intestinal tract with plastic rope, injuries inflicted on him by an adult bird, inflammation in the eye area, death from hunger or the accumulated impact of the above factors could all serve as the probable causes of its death.

Ingestion of plastic debris has currently been documented for 164 out of 406 seabird species $(40 \%)$, with this being less visible than entanglement [20]. It is known that the likelihood of plastic ingestion by seabirds decreased with the increase in distance further to the south off the Antarctic convergence [7]. At the same time, according to the subject of this message, one of such probabilities of erroneous ingestion of macroplastic by an emperor penguin came to pass directly off the coast of Antarctica. According to a recent review publication on the ingestion of plastic by seabirds [20], the unique account of the ingestion of macroplastic by emperor penguins at Mirny was first established for this Antarctic penguin. Currently, obtaining such evidence refers to the category of difficult to prove occurrences. It should be noted, however, that evidence exists of macroplastics detected in petrels breeding in Antarctica [10], and the presence of microplastics in the droppings of gentoo penguins Pygoscelis papua from populations in Antarctica and sub-Antarctica [21].

Plastic ingestion has been recorded in south polar skuas. Green plastic wrapping was found in two of 55 pellets collected in 2012 and 2015 with one of the pellets containing only plastic. Unlike natural skuas pellets, which have a solid consistency, plastic pellets easily fell apart during examination. Another pellet had minor inclusions of macroplastic (Figure 2). Both pellets were more than half the normal pellet size for south polar skuas. The most likely route for plastic to find its way into the digestive system of skuas is through their visit to the Mirny food waste dump. The ingestion of macroplastics by skuas, apparently, did not have a negative effect on them, nor lead to death, being released in the form of pellets. 


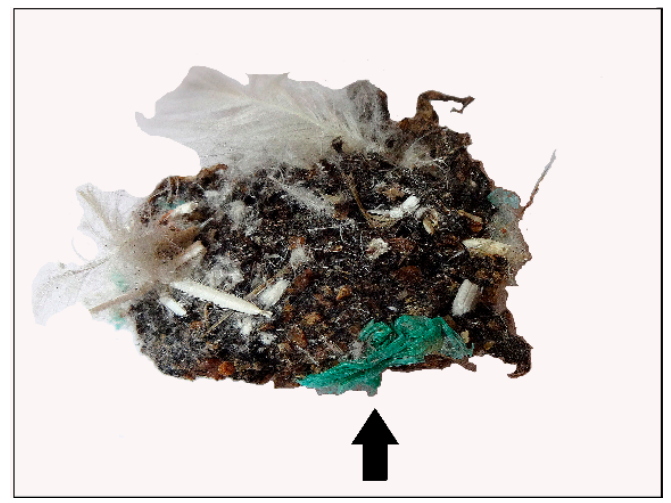

Figure 2. One of the pellets of the south polar skua (Catharacta maccormicki) with a green plastic fragment (shown by the black arrow), found in 2012/2013 and 2015/2016 in the Haswell archipelago (photo by the author).

Unlike Antarctic penguins, the ingestion of macroplastic fragments by south polar skuas is more common. Skuas are one of the few breeding seabirds in Antarctica that gravitate towards human settlements, visiting, to a greater or lesser extent, the territories of the year-round occupied Antarctic stations, bases or seasonal field camps. Previously, in such places of human activity, skuas were attracted by garbage dumps and the possibility of utilizing available food resources, for example [22,23]. In this respect, the Mirny station was no exception [16,24]. In the recent past, kitchen refuse and garbage was found in the diet of south polar skuas in continental Antarctica, for example [25,26]. Garbage dumps may have been the source of the plastic entering the digestive system of the skuas. An example of this is the 16 discovered and surveyed pellets of south polar skuas from Green Lake on Ross Island (Antarctica), where at the end of the 20th century many of them contained plastic [27]. On the whole, recent accounts of the swallowing of marine debris have been documented in five (27.8\%) of 18 species of the order Sphenisciformes and in 55 (39.6\%) of 139 species of the order Charadriiformes [20].

\section{Conclusions}

The recent discovery of interactions between emperor penguins, Adélie penguins and south polar skuas with macroplastics at Mirny clearly indicates that such pollution is not an random, although such cases are still rare in high Antarctic latitudes. A targeted and comprehensive survey of breeding populations of seabirds in the Haswell Islands will allow us to gain more objective insights and assessments of the true scale of threats from the interactions of Antarctic birds with macroplastics, as well as to develop a strategy to reduce existing and potential risks. The need to include this problem in the health monitoring program for terrestrial biota of the Haswell archipelago is obvious.

Funding: This research received no external funding.

Acknowledgments: I thank Jukka Jokimäki (Editor in Chief) and two anonymous reviewers for their useful comments and Victor Sergeevich Gusev for the language corrections. The registration of plastic in seabirds at Mirny became possible thanks to the author's participation in the 57th and 60th Russian Antarctic expeditions.

Conflicts of Interest: The author declares that he has neither political nor academic conflict of interest. The author is responsible for the results and the interpretations of the materials in this article.

\section{References}

1. Ryan, P.G. A brief history of marine litter research. In Marine Anthropogenic Litter; Bergmann, M., Gutow, L., Klages, L.M., Eds.; Springer: Berlin, Germany, 2015; pp. 117-140.

2. Jambeck, J.R.; Geyer, R.; Wilcox, C.; Siegler, T.R.; Perryman, M.; Andrady, A.; Narayan, R.; Law, K.L. Plastic Waste Inputs from Land into the Ocean. Science 2015, 347, 768-771. [CrossRef] [PubMed]

3. Barnes, D.K.A.; Galgani, F.; Thompson, R.C.; Barlaz, M. Accumulation and fragmentation of plastic debris in global environments. Philos. Trans. R. Soc. B: Biol. Sci. 2009, 364, 1985-1998. [CrossRef] 
4. Cole, M.; Lindeque, P.; Halsband, C.; Galloway, T.S. Microplastics as contaminants in the marine environment: A review. Mar. Pollut. Bull. 2011, 62, 2588-2597. [CrossRef] [PubMed]

5. Derraik, J.G.B. The pollution of the marine environment by plastic debris: A review. Mar. Pollut. Bull. 2002, 44, 842-852. [CrossRef]

6. Wilcox, C.; Sebille, E.V.; Hardesty, B.D. Threat of plastic pollution to seabirds is global, pervasive, and increasing. Proc. Natl. Acad. Sci. USA 2015, 112, 11899-11904. [CrossRef] [PubMed]

7. Ainley, D.G.; Fraser, W.R.; Spear, L.B. The Incidence of Plastic in the Diets of Antarctic Seabirds. In Proceedings of the Second International Conference on Marine Debris, Honolulu, HI, USA, 2-7 April 1989; pp. 682-691.

8. Suaria, G.; Perold, V.; Lee, J.R.; Lebouard, F.; Aliani, S.; Ryan, P.G. Floating macro- and microplastics around the Southern Ocean: Results from the Antarctic Circumnavigation Expedition. Environ. Int. 2020, 136, 105494. [CrossRef] [PubMed]

9. Ryan, P.G. The incidence and characteristics of plastic particles ingested by seabirds. Mar. Environ. Res. 1987, 23, 175-206. [CrossRef]

10. Van Franeker, J.A.; Bell, P.J. Plastic ingestion by petrels breeding in Antarctica. Mar. Pollut. Bull. 1988, 19, 672-674. [CrossRef]

11. Slip, D.J.; Green, K.; Woehler, E.J. Ingestion of anthropogenic articles by seabirds at Macquarie Island. Mar. Ornithol. 1990, 18, 74-77.

12. Woehler, E.J. Two records of seabird entanglement at Casey, Antarctica. Mar. Ornithol. 1990, 18, 72-73.

13. Auman, H.J.; Woehler, E.J.; Riddle, M.J.; Burton, H. First evidence of ingestion of plastic debris by seabirds at sub-Antarctic Heard Island. Mar. Ornithol. 2004, 32, 105-106.

14. Laist, D.W. Impacts of marine debris: Entanglement of marine life in marine debris including a comprehensive list of species with entanglement and ingestion records. In Marine Debris: Sources, Impacts and Solutions; Coe, J.M., Rogers, B.D., Eds.; Springer: Berlin, Germany, 1997; pp. 99-141.

15. Ryan, P.G. Effects of ingested plastic on seabird feeding: Evidence from chickens. Mar. Pollut. Bull. 1988, 19, 125-128. [CrossRef]

16. Golubev, S.V. Injuries of Webs on the Feet of South Polar Skuas Catharacta Maccormicki: Results of Studying Active Obliged Aggregations. Am. J. Life Sci. 2018, 6, 65-73. [CrossRef]

17. Golubev, S.V. Aberrant and deformed Antarctic penguins and unusual eggs. Notornis 2020, 67, 459-468.

18. Ryan, P.G. Entanglement of birds in plastics and other synthetic materials. Mar. Pollut. Bull. 2018, 135, 159-164. [CrossRef]

19. Golubev, S.V. Antarctic Diary: Notes by an Ornithologist; Filigree: Yaroslavl, Russia, 2014; 335p. (In Russian)

20. Kühn, S.; Bravo Rebolledo, E.L.; van Franeker, J.A. Deleterious effects of litter on marine life. In Marine Anthropogenic Litter; Bergmann, M., Gutow, L., Klages, L.M., Eds.; Springer: Berlin, Germany, 2015; pp. $75-116$.

21. Bessa, F.; Ratcliffe, N.; Otero, V.; Sobral, P.; Marques, J.C.; Waluda, C.M.; Trathan, P.N.; Xavier, J.C. Microplastics in gentoo penguins from the Antarctic region. Sci. Rep. 2019, 9. [CrossRef]

22. Micol, T.; Jouventin, P. Long-term population trends in seven Antarctic seabirds at Pointe Geologie (Terre Adelie). Human impact compared with environmental change. Polar Biol. 2001, 24, 175-185. [CrossRef]

23. Chwedorzewska, K.J.; Korczak, M. Human impact upon the environment in the vicinity of Arctowski Station, King George Island, Antarctica. Pol. Polar Res. 2010, 31, 45-60. [CrossRef]

24. Starck, W. The avifauna of Haswell Island (East Antarctica) in summer of 1978/79. Pol. Polar Res. 1980, 1, 183-196.

25. Fowler, J.A. Antarctic skuas at Vanda Station, Antarctica. Notornis 1973, 20, 381-382.

26. Reinhardt, K.; Hahn, S.; Peter, H.-U.; Wemhoff, H. A review of the diets of southern hemisphere skuas. Mar. Ornithol. 2000, 28, 7-19.

27. Young, E.C. Diet of the south polar skua Catharacta maccormicki determined from regurgitated pellets: Limitations of a technique. Polar Rec. 1990, 26, 124. [CrossRef]

Publisher's Note: MDPI stays neutral with regard to jurisdictional claims in published maps and institutional affiliations. 